\title{
ENSINO E APRENDIZAGEM DA LEITURA E DA ESCRITA À LUZ DE CONTRIBUIÇÕES DA TEORIA WALLONIANA: CONSTRUÇÃO DE POSSIBILIDADES PSICOPEDAGÓGICAS NO CONTEXTO ESCOLAR
}

\author{
Silvia Aparecida Santos de Carvalho ${ }^{1}$ \\ Prefeitura Municipal de São Paulo
}

\section{RESUMO}

A presente elaboração tem por objetivo apresentar a pertinência da teoria de Henri Wallon para o desenvolvimento de práticas de ensino e de aprendizagem da leitura e da escrita. Será realizado um movimento de recuperação de processos de ensino e de aprendizagem vivenciados pela autora, que na ocasião era professora de um grupo de alunos em processo de alfabetização. Na análise aqui empreendida, desses processos de ensino e de aprendizagem serão destacadas práticas psicopedagógicas vivenciadas no contexto escolar que objetivaram a superação de dificuldades de aprendizagem da leitura e da escrita nos anos iniciais da escolarização.

Palavras chaves: Dificuldades de Aprendizagem; Leitura e Escrita; Henry Wallon

\footnotetext{
${ }^{1}$ Silvia Aparecida Santos de Carvalho. Doutora em Educação e Psicopedagoga. Prefeitura Municipal de São Paulo - silviacarvalho1@gmail.com
} 


\title{
TEACHING AND LEARNING READING AND WRITING IN THE LIGHT OF CONTRIBUTIONS OF WALLONIAN THEORY: CONSTRUCTION OF PSYCHOPEDAGOGICAL POSSIBILITIES IN THE SCHOOL CONTEXT
}

\begin{abstract}
This elaboration aims to present the relevance of Henri Wallon's theory for the development of teaching and learning practices in reading and writing. There will be a movement to recover the teaching and learning processes experienced by the author, who at the time was a teacher of a group of students in the process of literacy. In the analysis undertaken here, these teaching and learning processes will highlight psychopedagogical practices experienced in the school context that aimed to overcome difficulties in learning to read and write in the early years of schooling.
\end{abstract}

Keyswords: Learning Disabilities; Reading and writing; Henry Wallon

\section{Introdução}

A identificação da pertinência da teoria de Henri Wallon para o desenvolvimento de significativos processos de aprendizagem da leitura e da escrita pode ser alcançada, indubitavelmente, quando temos como objeto de estudo a fecundidade da teoria walloniana para a elaboração de processos de ensino.

Então, para responder a esse desafio investirei num movimento de recuperação de práticas que envolveram situações de leitura e de escrita destacadamente desafiadoras, que contaram com importantes dificuldades de aprendizagem e esforço de elaboração de práticas de ensino que pudessem ser significativas, vivenciadas no ambiente escolar.

Será a partir do exercício reflexivo de recuperação dessas práticas que apontarei o quanto o pensamento walloniano lhes confere profundo sentido e o quanto, a partir daí, pode representar considerável qualificação para a prática psicopedagógica.

\section{Numa escola, perto de um Rio, uma nova chance...}

Quando ingressei em 1991 como professora efetiva do ensino de 1o grau - 1a a 4a série, numa escola periférica da rede municipal de ensino de São Paulo, eu já tinha alguma experiência na profissão, acumulada em alguns anos vivenciados em algumas escolas particulares bem como na rede estadual de ensino. Eu tinha concluído há algum tempo o curso de Magistério - nível de 2o grau - e estava cursando a Graduação em Pedagogia na Pontifícia Universidade Católica de São Paulo - PUC-SP.

Esses anos anteriores vivenciados em classes de alfabetização de crianças das séries iniciais provocaram muitas inquietações advindas da identificação da dificuldade que tinham meus alunos em se alfabetizar e me inspiravam também um desejo grande de realizar algo significativo, que realmente pudesse contribuir para o êxito da aprendizagem deles. 
Ensino e aprendizagem da leitura e da escrita à luz de contribuições da teoria walloniana: construção de possibilidades psicopedagógicas no contexto escolar

Contudo, eu não tinha ideia de estar prestes a vivenciar uma das mais importantes experiências que tive em minha carreira profissional, na educação da rede pública municipal, determinantemente significativa para as escolhas teórico-metodológicas que fiz posteriormente.

O ano de 1991 já era o terceiro ano em que Luiza Erundina de Souza ocupava o cargo de prefeita da cidade de São Paulo e até 27 de maio desse mesmo ano teve como Secretário da Educação Municipal Paulo Reglus Neves Freire, o ilustre profo Paulo Freire, com o qual pude me encontrar por diversas vezes para conversar, como ele próprio gostava de dizer, nas reuniões que fazia com professores, sobretudo, com alfabetizadores ${ }^{1}$.

Inspirada, então, por estudos e reflexões freirianas, desenvolvidos no curso de Pedagogia da PUC-SP e nos grupos de formação promovidos na rede de ensino municipal de São Paulo, elaborei e propus, ao final do ano de 1991, para a Secretaria Municipal da Educação, um projeto para ser aplicado com alunos multi repetentes, alunos frequentes na escola em que trabalhava como professora alfabetizadora, que não conseguiam ser promovidos para a $2 \underline{a}$ série. 0 sistema de promoção ainda era seriado e uma vez que esses alunos não estavam alfabetizados eles permaneciam na 1a série 2, 3, 4 anos sem aprender a ler e a escrever. ${ }^{2}$

De acordo com as regras do ensino municipal de formação de classes deveríamos compor uma turma de 30 alunos. Indubitavelmente uma classe com dificuldades na alfabetização deveria contar com um número menor de alunos, mas por causa da demanda municipal e da demanda identificada na escola não foi possível ser assim. Além disso, o campo de disputas internas da escola era intenso... havia uma dúvida entre os professores sobre a verdadeira validade que esse projeto poderia ter. Observar que determinadas práticas pedagógicas, sustentadas e valorizadas pelas políticas educacionais até então implementadas, tinham contribuído para produzir uma massa de alunos que não estava alfabetizada era reconhecer erros, equívocos, e isso não era muito confortável para a equipe de professores. Por isso, a classe a ser formada não poderia ser privilegiada, por exemplo, com a diminuição do número de alunos porque, na compreensão hegemônica do grupo docente, com um número menor de integrantes era mesmo possível alfabetizar qualquer um. $O$ argumento para a não alfabetização se apoiava, entre outros motivos, também no número de crianças de cada sala. Além disso, eu tinha estabelecido como o primeiro critério de formação dessa turma que seriam considerados os alunos que tinham 10 anos ou mais de idade e que ainda estavam presos na 1a série. E nessa situação estavam 30 alunos, o número mínimo estabelecido na rede municipal para compor uma classe.

Depois de reunir os alunos que estavam em tal situação estabeleci o 2ㅇ critério. Todos seriam promovidos para a 2a série e assim já começaríamos um trabalho com a autoestima de cada um deles.

Com a autorização da Secretaria de Educação formamos a $2^{2} \underline{a}$ série $A$. A letra $A$ também não foi por acaso. Esses alunos estavam culturalmente acostumados a serem considerados como sempre os últimos, aqueles que dificilmente iriam conseguir aprender, para os quais os investimentos educacionais não renderiam resultados satisfatórios.

Em 27 de maio de 1991 Paulo Freire deixou a Secretaria Municipal de Educação de São Paulo e foi substituído por Mario Sérgio Cortella.

2 O sistema de ensino seriado de acordo com a Lei de Diretrizes e Bases da Educação - LDB 5692/71 pode ser alterado a partir do que foi determinado no artigo V - capítulo II da Lei de Diretrizes e Bases da Educação Nacional - LDBEN - $9394 / 96$ em vigor a partir de 20 de dezembro de 1996. Na rede municipal de ensino, a proposta de alterar o sistema de ensino seriado pelo sistema de ensino em ciclos de aprendizagem foi indicada e defendida pela primeira vez pelo Governo da Prefeita Luiza Erundina de Souza, no Regimento Comum das Escola Municipais - RCEM - 1992. 
Negros, pobres, moradores da favela localizada aos fundos do muro da escola, moravam sem saneamento básico, ficavam a mercê de enchentes provocadas pela chuva que fazia o Rio do Fogo, rio que passava entre a favela e a escola e que recebia logo próximo a sua nascente detritos de uma usina de tintas, transbordar, enchendo de água poluída as suas casas, com um número que não nos atrevemos a imaginar de ratos tentando também se salvar na correnteza. Nessa situação ficavam perigosamente expostos a surtos de leptospirose. Depoimentos dados por pais e moradores do bairro na pesquisa feita pelos professores para estudar a realidade vivida pela comunidade usuária da escola - essa era a política educacional implementada, o currículo era organizado a partir desses estudos porque deveria contribuir para a emancipação da população - relataram que a correnteza demorava dias para diminuir e as crianças ficavam presas nas camas superiores de beliches para se protegerem dos ratos $\mathrm{e}$ da poluição.

Esses meninos e meninas dificilmente teriam uma chance de permanecer na escola. Excluídos economicamente, socialmente, culturalmente e pelo sistema educacional estavam prestes a evadir.

Então, nessa conjuntura, em fevereiro de 1992, iniciei o trabalho com eles.

\section{Imagem 1}

Plano de Desenvolvimento do Projeto de Alunos Multi-repetentes

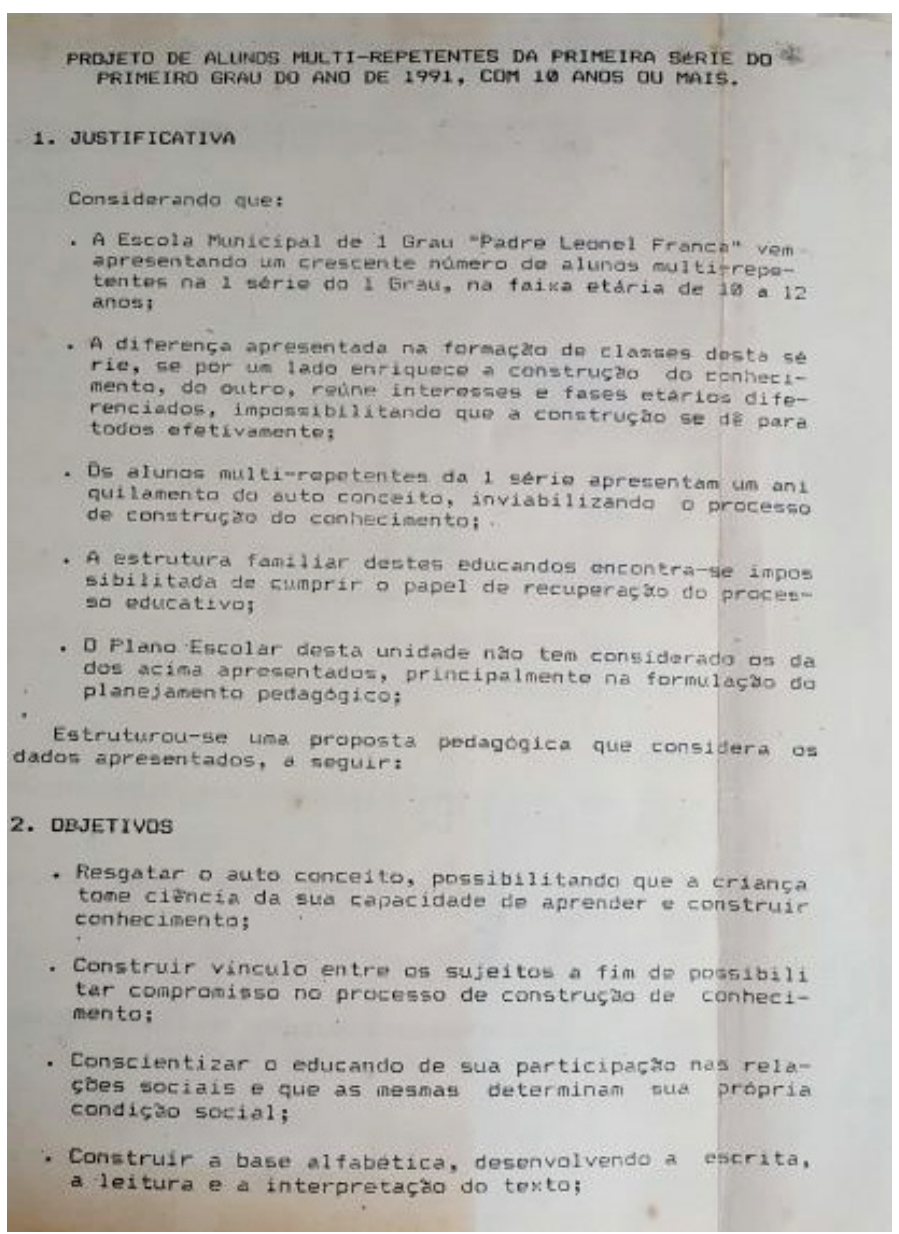

Fonte: Arquivo pessoal da autora - 1991 
Ensino e aprendizagem da leitura e da escrita à luz de contribuições da teoria walloniana: construção de possibilidades psicopedagógicas no contexto escolar

\section{Imagem 2}

\section{Plano de Desenvolvimento do Projeto de Alunos Multi-repetentes}

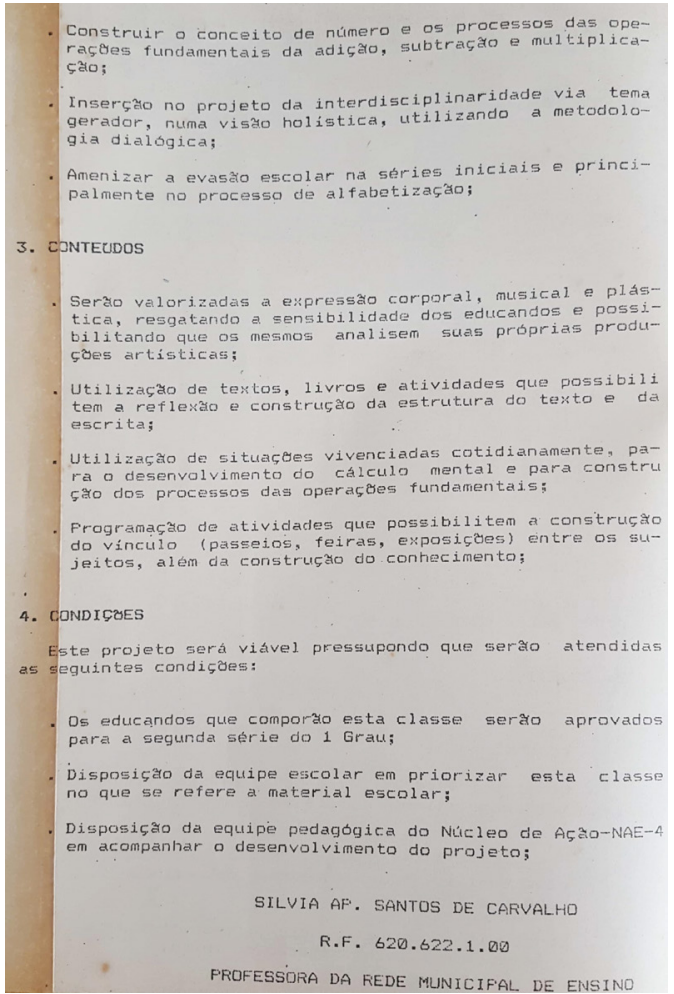

Fonte: Arquivo pessoal da autora - 1991

\section{Imagem 3}

Lista de Alunos componentes da $2^{a}$ série A - Projeto de Alunos Multi-repetentes

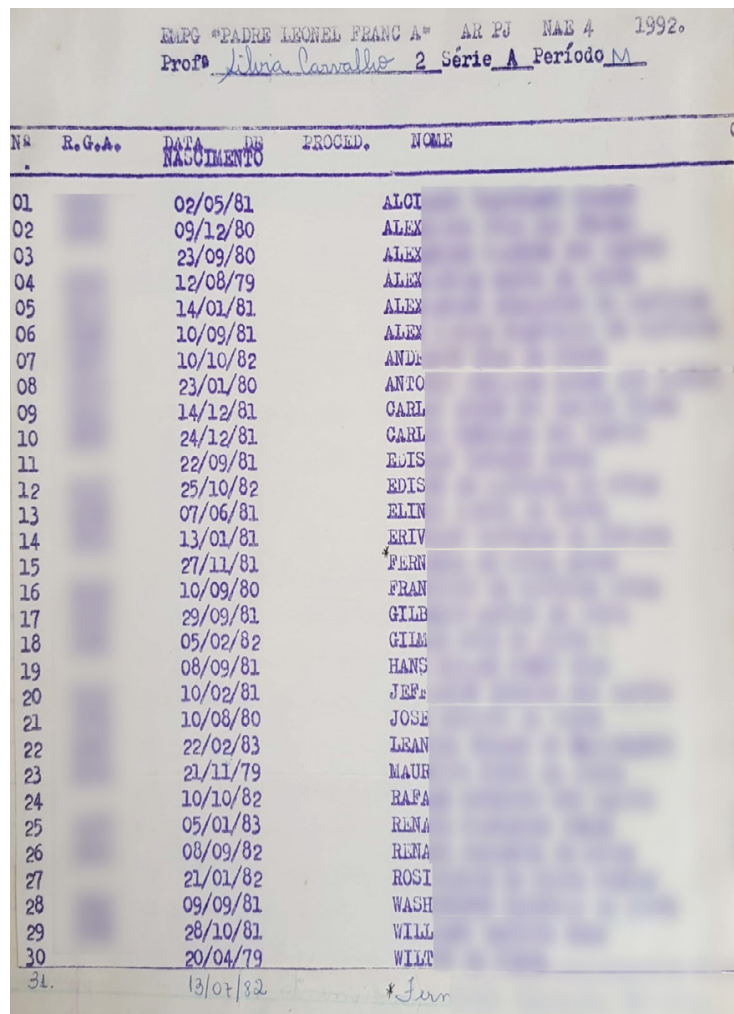

Fonte: Arquivo pessoal da autora - 1992 


\section{E a correnteza levou... levou quase tudo... menos a certeza de que era preciso continuar!!!}

No primeiro dia de aula o caos se fez!!!! Por orientação minha, meus alunos não fariam a fila indiana costumeiramente organizada para dirigir os alunos pequenos para as suas salas de aula no início do período. Os meus alunos, que eram visivelmente bem maiores, foram orientados a subir sem fila para as salas que ficavam no 10 andar do prédio escolar. Acompanhados por mim, fomos os primeiros a subir... Éramos a primeira classe, a 2a $\mathrm{A}$.

Foi uma verdadeira apresentação de violência... auditiva, física, verbal. Uma gritaria regada a pontapés e palavrões compôs a cena inicial do período e logo percebi pelos olhares que os outros professores destinaram a mim e também pela minha própria observação que seria difícil... Naquele momento tive a certeza que necessitaria de muita iluminação teórica e inspiração metodológica.

Entramos! Não era possível falar e então, gritei... E logo me veio uma sensação de fracasso porque era tudo que eu não queria fazer... repetir práticas vivenciadas cotidianamente na escola por aqueles meninos e meninas.

Coloquei todos sentados... foi arduamente cansativo... E todo o planejamento que tinha para a primeira aula foi embora com a correnteza do Rio do Fogo... Sim... a correnteza levou quase tudo... mas, resignadamente, mantive a certeza de que era preciso continuar!

Parei de gritar e aos poucos todos foram se aquietando e então pude ligeiramente me apresentar... propus então que se apresentassem para mim, falando seus nomes e sobre o que esperavam para aquele ano... Não pude recolher muitas respostas... não tínhamos ainda construído algum vínculo que fizesse aquele momento merecer alguma confiança... foi bastante difícil...

O primeiro mês de trabalho foi pautado pela construção de regras... eu tinha inicialmente um plano para desenvolver essa questão, mas com uma intensidade infinitamente diferente da que observei como necessária. Foram semanas discutindo como iríamos nos organizar, refletindo sobre o modo de relacionamento vivenciado no grupo. Nessas condições fui observando a necessidade de promover um espaço de aprendizagem que considerasse integradamente temas como expressividade, emoção, gestualidade, movimento, representação mental, pensamento discursivo. Nas contribuições dos estudos de Henri Wallon, extremamente importantes para compreender a profundidade dessas necessidades, encontro sentido nas ações que desenvolvi para favorecer a aprendizagem daqueles adolescentes.

Nas palavras de Galvão (1993), Wallon entende que “... não há forma de se dirigir à inteligência da criança sem se dirigir à criança como um todo". (GALVÃO, 1993, p. 35). Somente assim haverá grandes chances de atender a criança em suas diversas necessidades e impulsionar o seu desenvolvimento favorecendo sua aprendizagem.

Quando identificamos que para Wallon

... a Escola não deve dissociar a formação da inteligência da formação da personalidade, pois a inteligência tem status de parte no todo constituído pela pessoa e seu desenvolvimento está ligado ao das outras esferas constitutivas deste todo (GALVÃO, 1993, p.35) ...

É possível entender que a prática educativa não deve ter em vista apenas o desenvolvimento intelectual. Mesmo tendo a tarefa muito importante de difundir o conhecimento historicamente acumulado, a Escola deve assumir também o compromisso de proporcionar ao indivíduo as condições para desenvolver-se nos aspectos afetivos e psicomotores. 
Ensino e aprendizagem da leitura e da escrita à luz de contribuições da teoria walloniana: construção de possibilidades psicopedagógicas no contexto escolar

Na Psicogenética de Wallon ganha destaque os campos funcionais do Movimento que se refere à ação direta sobre o meio físico e que se constitui como base das emoções; da Manifestação Afetiva, que se refere às emoções propriamente; da Inteligência, que nasce das emoções e que resulta no desenvolvimento da inteligência discursiva, expressa por meio da linguagem e por fim da Pessoa, constituída no processo de construção da consciência de si, que se desenvolve em concomitância com o desenvolvimento da consciência do outro.

Compreender esses campos funcionais estudados por Wallon qualifica o trabalho psicopedagógico e pode contribuir significativamente no processo de preparação das ações promotoras de aprendizagem.

Nos primeiros seis meses de trabalho o investimento em aprofundar as relações afetivas do grupo foi bastante intenso. Junto com elas pensamos bastante sobre nosso corpo no espaço. Como posso ocupar um espaço no grupo em que eu seja respeitado, mas que também possa respeitar meus amigos? Essa foi uma questão geradora que ocupou várias de nossas aulas. A exploração da motricidade, exercitando a consciência a respeito dos movimentos, de sua intencionalidade, foi conferindo oportunidades maravilhosas de transformação nos comportamentos daqueles meninos e meninas.

Conforme o pensamento walloniano é muito importante que no contexto escolar seja ressignificado o lugar do movimento e sua importância para o processo de aprendizagem da criança.

Foi assim que desenvolvi um projeto de Capoeira com a turma. Profundamente vinculada com a cultura daqueles meninos e meninas a capoeira parecia ser uma terapia intensamente vivida com prazer, com emoção, com muita atenção. A partir dela foi possível explorar tentativas de desenhar. Até então, tudo que estava relacionado direta ou indiretamente com a ação de pegar no lápis para escrever ou desenhar tinha sido repudiado com vigor. Mas o trabalho intenso de corpo e de reflexão sobre os movimentos propostos na luta, sobre o que significavam, a questão da defesa que a capoeira representou na resistência à escravidão e como ela era significativa para uma defesa que eles precisavam vivenciar também, fomos construindo um forte vínculo afetivo entre nós. E assim, as atividades com lápis e papel foram sendo incluídas em nossa rotina.

Fizemos muitas rodas de conversa, a todo o momento, especialmente quando surgiam conflitos. Houve aulas e períodos inteiros nos quais nos dedicamos exclusivamente a essa questão. E para dar conta da necessidade do grupo, sem deixar de perceber as necessidades individuais de cada um também foi um grande desafio na construção dessa convivência. Em todos os momentos de nossas reflexões fazíamos um exercício de autoconhecimento. Muito importante para o aprimoramento emocional individual e coletivo. As contribuições de Wallon que dão atenção para o campo funcional da Pessoa são fundamentais para observar a importância do processo de individuação pelo qual passam os indivíduos. No momento inicial de vida todos nos encontramos num estado de socialização máxima e, por isso, não temos consciência de nós mesmos, por nos enxergarmos confundidos com o meio externo. $O$ desenvolvimento possibilitará que um processo de constituição da consciência de si próprio vá operando a diferenciação entre quem somos de quem é o outro. $\mathrm{E}$ a interação é fundamental para o que processo de individuação progressiva possa ocorrer. Comportamentos de oposição, negação do outro, característicos da adolescência, serão fundamentais para o processo de individuação e foi preciso refletir muito sobre isso para que todos pudessem conhecer melhor a si próprios e melhorar a maneira de estabelecer as relações no grupo.

Com a agressividade reduzida e aos poucos sendo significativamente substituída pela confiança e afetividade ampliávamos as atividades que envolviam lápis e papel. Contudo, ainda não era possível pedir para escrever e a leitura era feita muita timidamente... com muita desconfiança ainda. Certamente, nesse momento ainda havia um longo caminho a percorrer e minha preocupação com a alfabetização se tornava cada vez maior... Era importante, muito importante que esses meninos e meninas vencessem esse desafio até o final do ano... Importante para eles e para a sua autoestima, importante para mim que queria ver o êxito daqueles meninos e meninas 
que por muito anos haviam sido desencorajados no processo de aprender, importante para a política educacional daquele governo que tinha um compromisso político pedagógico para honrar junto à comunidade educativa.

\section{Sentir... Gostar... Confiar... Escrever... Ler... Um recomeço!!!}

Wallon nos alerta que, no que diz respeito a inteligência, é importante atentar que ela nasce nas emoções. Inteligência e Emoção caminham indissociavelmente e conforme a Inteligência vai ocupando espaço importante na constituição do aparelho psíquico, inteligência e emoção vão se constituindo numa relação de antagonismo e conflito.

Do pensamento sincrético ao pensamento categorial, conceitual, a inteligência vai se desenvolvendo. E para que esse desenvolvimento se dê, é fundamental que a criança interaja com os produtos da cultura e os incorpore ao seu modo próprio de pensar.

Essa compreensão do pensamento walloniano nos ajuda na identificação da pertinência dos investimentos que fizemos no campo funcional da afetividade e como esses foram fundamentais para a reflexão sobre como seria escrever, ler, atribuindo significados diferentes dos que o grupo já tinha para essas práticas.

O primeiro investimento foi ler e escrever sobre os sentimentos... Mimeografei uma música de Beto Guedes que ao falar da Primavera fala também da necessidade de refazermos nossa compreensão sobre a realidade que vivemos... muito significativa para o nosso momento.

Ouvimos... ouvimos mais uma vez e convidei todos para cantar... Sugeri, para quem não sabia a letra, a leitura da música... Distribuí as folhas atenta às reações... que me pareciam menos de rejeição... com um quê de desafio misturado com uma certa aflição... Começaram então a cantar acompanhando no papel... e logo a leitura desenrolou... com felicidade... tínhamos alcançado um objetivo importante.

\section{Imagem 4}

1a Lição Sistematizada de Leitura e Escrita do Projeto de Alunos Multi-repetentes

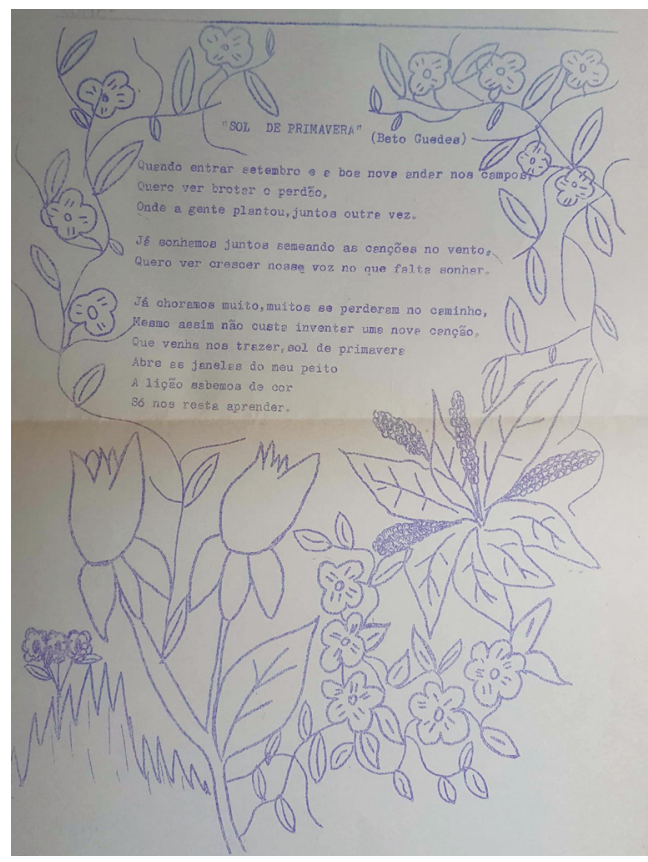


Ensino e aprendizagem da leitura e da escrita à luz de contribuições da teoria walloniana: construção de possibilidades psicopedagógicas no contexto escolar

A partir daí, os muros que pareciam intransponíveis começaram a cair... O investimento na leitura e escrita - sempre tínhamos um motivo para ler e escrever, sempre buscando a ressignificação - desdobraram-se em conhecimento do funcionamento do sistema de escrita alfabética.

\section{Imagem 5}

Sondagem de Níveis de Compreensão de Escrita

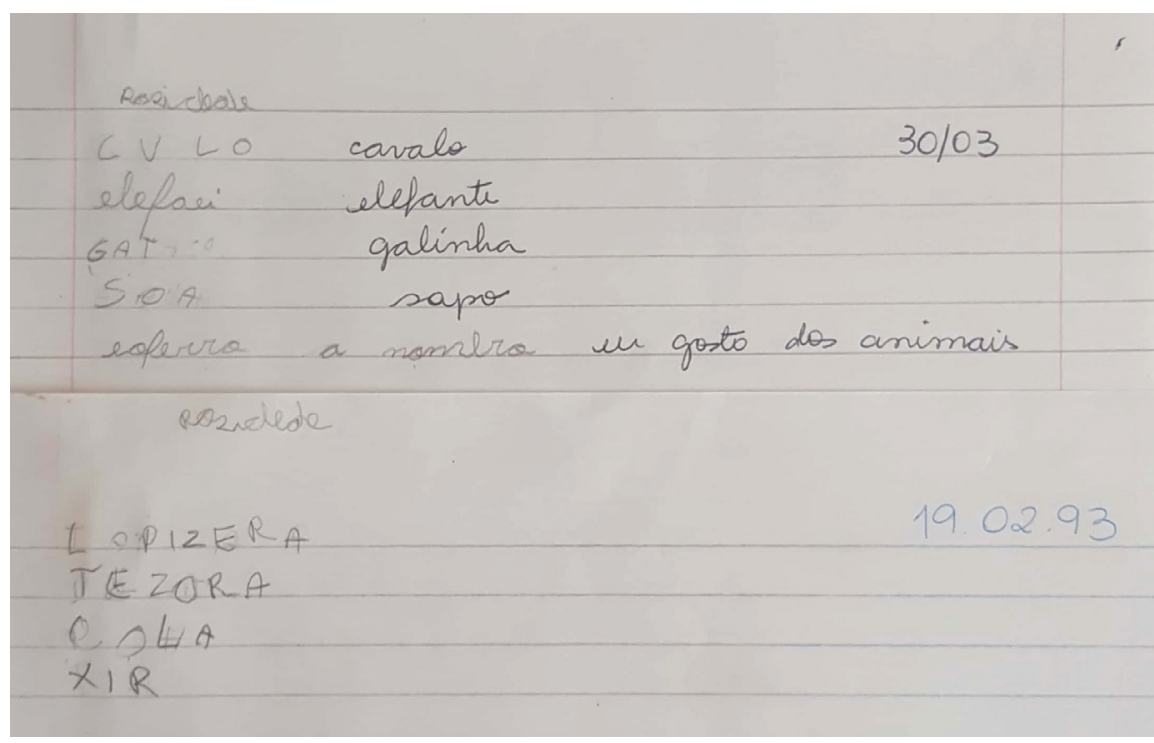

Fonte: Arquivo pessoal da autora - 1992

Imagem 6

Sondagem de Níveis de Compreensão de Escrita

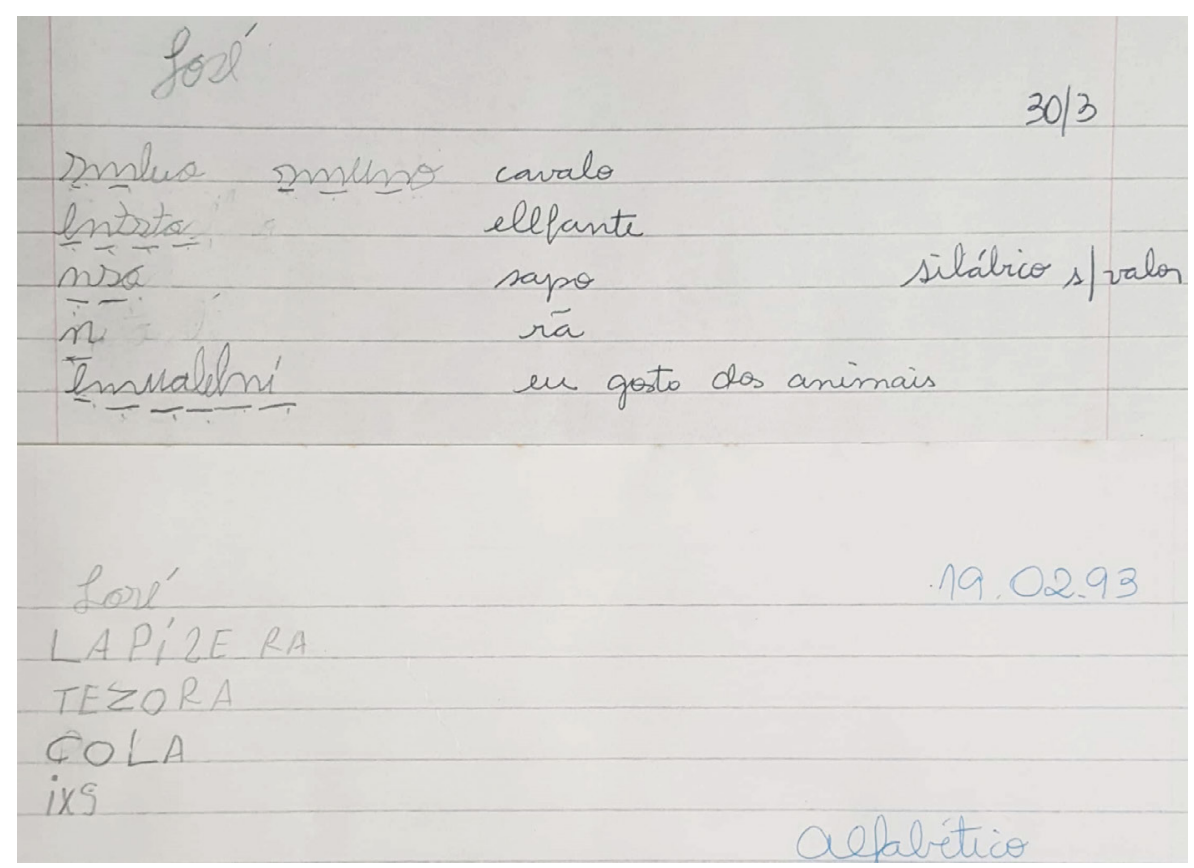

Fonte: Arquivo pessoal da autora - 1992 
Imagem 7

Sondagem de Níveis de Compreensão de Escrita

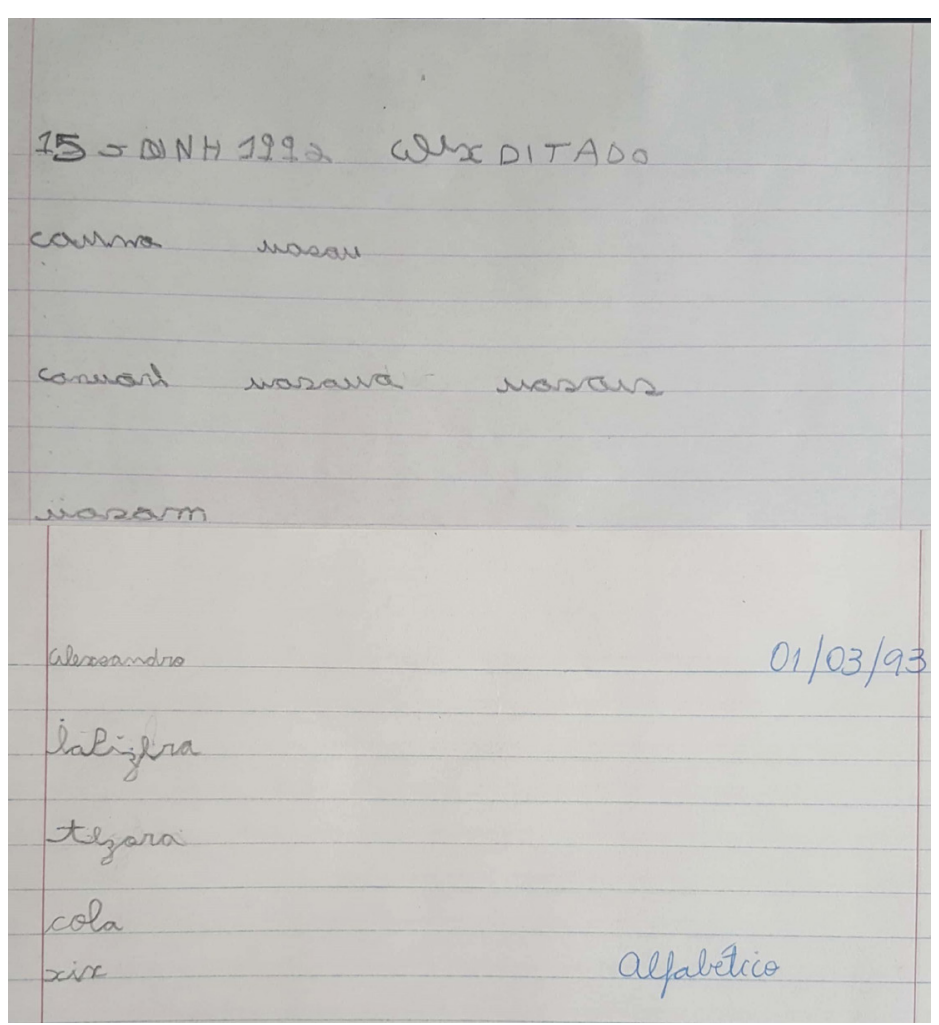

Fonte: Arquivo pessoal da autora - 1992

\section{Imagem 8}

Sondagem de Níveis de Compreensão de Escrita

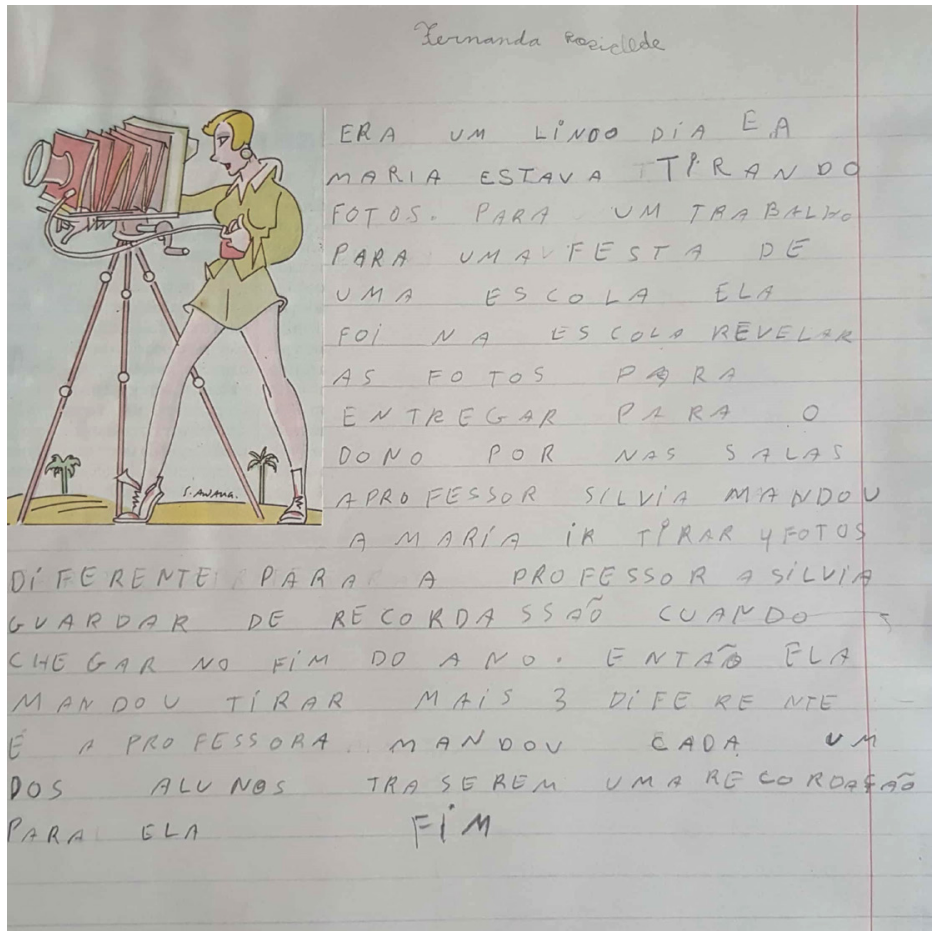

Fonte: Arquivo pessoal da autora - 1992 
Ensino e aprendizagem da leitura e da escrita à luz de contribuições da teoria walloniana: construção de possibilidades psicopedagógicas no contexto escolar

Um ano de trabalho foram suficientes para que eles iniciassem o processo de compreensão do funcionamento do sistema de escrita... Ressignificaram as práticas de leitura, conseguiram recuperaram o gosto por saber, por aprender. Progrediram nas capacidades linguísticas e na compreensão e ampliação da linguagem oral e escrita.

Para Wallon, o pensamento progride sustentado pela linguagem. Se a linguagem exprime o pensamento ela também opera como estruturadora do mesmo. Quando substitui a coisa, a linguagem possibilita a formação simbólica desses objetos, que podem, então, no plano mental serem operados, desvinculadamente da experiência pessoal e imediata. (GALVÃO,1995)

Como característica principal do pensamento infantil, Wallon aponta o sincretismo que

... costuma designar o caráter confuso e global do pensamento e percepção infantis (...) esta globalidade está presente em vários aspectos da atividade mental, que percebe e representa a realidade de forma indiferenciada. No pensamento sincrético encontram-se misturados aspectos fundamentais, como o sujeito e o objeto pensado, os objetos entre si, os vários planos do conhecimento, ou seja, noções e processos fundamentais de cuja diferenciação dependem os progressos da inteligência. (GALVÃO, 1995, p. 57)

Podemos identificar claramente, a partir da contribuição do pensamento walloniano, a evolução dos adolescentes expressa em suas escritas.

Com a intensificação do processo de simbolização o pensamento vai atingindo uma representação mais objetiva da realidade. Então, o pensamento sincrético vai dando lugar ao pensamento categorial e assim realizam-se diferenciações importantes no plano da pessoa e no desenvolvimento da consciência de si. O pensamento sincrético se reduz e o pensamento categorial ganha maior expressão no desenvolvimento da inteligência.

Conforme Galvão (1995), o pensamento categorial se configura na "... capacidade de formar categorias, ou seja, de organizar o real em séries, classes, apoiadas sobre um fundo simbólico estável. É uma função de diferenciação que favorece a objetivação do real." (GALVÃO, 1995, p.60) . A autora ainda se apoia nas palavras de Wallon para afirmar que

Objetivar o real é pensá-lo em potencial ou sob forma categorial, isto é, em sua eventual diversidade, o que tem o duplo efeito de tornar possíveis o controle das coisas e o ajustamento gradativo pensamento à realidade destas. (WALLON, 1980, p.752 apud GALVÃO, 1995, p.60).

Com um investimento intenso no desenvolvimento da afetividade, também nos ocupamos com a evolução do pensamento categorial. A compreensão do funcionamento do sistema de escrita alfabética comprova essa evolução.

\section{Considerações finais}

Sabemos e não é demais reconhecer que só foi possível realizar um trabalho como esse a partir do apoio que recebemos da Secretaria de Educação Municipal. A política educacional favoreceu fundamentalmente todo o desenvolvimento das atividades. Enxergo nesse apoio muita influência dos pressupostos teórico - metodológicos considerados no Plano Langevin-Wallon. A política educacional implementada entre 1989-1992 teve como princípios norteadores vários itens defendidos pelo Plano: a intenção de garantir o acesso de todos à cultura e ao conhecimento vistos como humanizadores; a preocupação de desenvolver a solidariedade entre os indivíduos; o repúdio à opressão e elevação da dignidade dos cidadãos; a adequação do sistema às necessidades de uma sociedade democrática e às possibilidades e características psicológicas do indi- 
víduo; o favorecimento máximo do desenvolvimento das aptidões individuais e a formação do cidadão; a substituição dos critérios econômicos por critérios baseados nas aptidões e potencialidades dos alunos, a serem observados por meio de orientação escolar e profissional; a efetiva democratização do ensino pela garantia da gratuidade do ensino em todos os níveis; a melhoria da situação dos professores (salarial, técnica e social); o aumento do percentual da receita destinado à Educação; os ciclos de ensino ${ }^{3}$ os quais deveriam ter estrutura diferenciada para atender ás especificidades das faixas etárias; o grau de responsabilidade da gestão da Escola.

Viver essa experiência foi extraordinário!!! Posso encontrar apoio para identificar a importância desse trabalho nas considerações desenvolvidas por Alexandroff (2012). No processo de pesquisa que realizou e culminou em sua dissertação de mestrado a autora aponta a possibilidade de haver a cura, a partir de atividades que possam promover a catarse e ressignificação do conceito que tem as crianças sobre si mesmas. Verifico a profundidade da afirmação de Alexandroff no trabalho desenvolvido com aquelas crianças... no desafio que aceitaram... na evolução que tiveram.

Observar hoje que os estudos da teoria walloniana conferem sentido e significado ao que vivi indubitavelmente me inspiram no processo de preparação da prática psicopedagógica. Muitas das práticas de ensino elaboradas e planejadas à luz de contribuições teóricas wallonianas guiam e sugerem percursos psicopedagógicos que, por sua vez, podem desenvolver processos de aprendizagem significativos na sala de aula. Considerar integradamente expressividade, emoção, gestualidade, movimento, representação mental, pensamento discursivo são conceitos chaves para o desenvolvimento do trabalho psicopedagógico nessa perspectiva.

A possibilidade de ler e escrever inaugurou um novo tempo para aquele grupo e, para além dos desdobros observados decorrentes das atividades desenvolvidas em nossa sala aula, parece ter inaugurado também um novo cenário para a vida daquelas pessoas. Por um movimento de organização daquela comunidade, encorajado nas atividades implementadas pela escola em seu projeto político pedagógico, o Rio do Fogo se transformou e a água turva, poluída pelos detritos depositados próximos a sua nascente pela usina de tintas, mudou de cor... E tudo parecia combinar com uma sensação, compartilhada entre nós, por mim e meus alunos, de que o futuro poderia ser diferente!

\section{Referências}

ALEXANDROFF, Marlene Coelho, O papel das emoções na constituição do sujeito. Construção Psicopedagógica. São Paulo-SP, 2012, vol.20, no 20.

GALVÃo, Izabel. Dimensões do Movimento. In: Henri Wallon: uma concepção dialética do desenvolvimento infantil. Petrópolis, RJ: Vozes, 1995.

GALVÃO, Izabel. Pensamento, Linguagem e Conhecimento. In: Henri Wallon: uma concepção dialética do desenvolvimento infantil. Petrópolis, RJ: Vozes, 1995.

GALVÃO, Izabel. Reflexão sobre a prática pedagógica: enfocando situações de conflito. In: Henri Wallon: uma concepção dialética do desenvolvimento infantil. Petrópolis, RJ: Vozes, 1995.

\footnotetext{
Os ciclos de ensino propostos para a Rede foram inspirados no Projeto Longevin Wallon. A Secretaria da Educação começava a estudar Wallon e percebia que a saída para a questão da multi repetência devia ser estudado com mais profundidade. Os Grupos de Formação, liderados por profissionais do DOT (Divisão de Orientação Técnica, da qual fazia parte a Profa Marlene C. Alexandroff, discutiram muito a questão, antes de implantar os ciclos na rede de ensino.
} 
Ensino e aprendizagem da leitura e da escrita à luz de contribuições da teoria walloniana: construção de possibilidades psicopedagógicas no contexto escolar

GALVÃO, Izabel. Uma reflexão sobre o pensamento pedagógico de Henri Wallon. In: Cadernos Ideias, construtivismo em revista. São Paulo, F.D.E., 1993.

KOLYANIK FILHO, Carol. Motricidade e aprendizagem: algumas implicações para a educação escolar. In: Construção Pedagógica, São Paulo-SP, dez. 2010. vol. 18, no 17, p.53-66.

WALLON, Henry. O papel do outro na consciência do eu. In: Psicologia e educação da infância. Lisboa, Estampa, 1975. 